\title{
O FEMININO CORPO DA NEGRURA
}

\section{Leda Maria Martins}

$U F M G$

REFEREAECIAS BIBUOGRŔFICAS

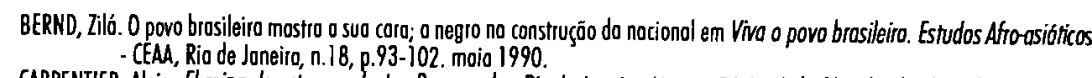

CARPENTIER, Alejo. El reino de este mundo. In: Dos novelas. Rio de Joneiro: Livorio Pógino Ltdo (distribuidoro), (s.d.) Tientos y Diterencios. Montevideo: Arco, 1973.

CHAMOJSEAU, Pothick Texoco. Trod. Roso Freire D'Aguiour. Sõo Poulo: Componhio dos Letros, 1993

DEPESTRE, René. Allelivio pour une femmejordin. Poris: Gollimord, 1981. Le mot de cocagne. Poris: Gollimord, 1979.

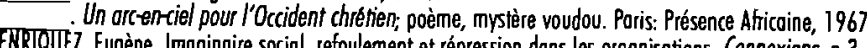

EONSCA, Eugène. Imoginaire sociol, refoulement et répression dons les organisations. Connexions, n.3, p. 65-93, 1972

ONSECA, Morio Nozareth Soores. Imogens e imaginórios: literaturo e reolidade culturol. In: Ensoios de Semiofica, n.2B-30, Belo Horizonte: FALE/UFMG, 1996

GISSANT Reinos negros em terros de morovithos. Belo Horizonte: FALENUFMG, 1993 (tese de Doutoroda, inédito).

Poéfique de la relation. Paris: Goillimard, 1990

TELERA, Lúcio. Escrevendo o noşóo. In: Literatura e diferenco. IV Congresso ABRALLC. Sõo Paulo: 1995.

KUNDERA, Milon. Beou commme une rencontre multiple. L'WFFl;; Littéroture/Philosophie/Art Science/Politique, Poris, n.34, 50 62, mai. 1991

MARTINON, Jeon-Pierre. 0 mito do literoturo. In: Gennie Luccioni et al. Atualidade do mito. Irod. Corlos Arthur $R$. Moscimento. Sä Poula: Duos Cidodes, 1970.

MARTINS, Ledo Mario. A ceno em sombros. Sõo Poulo: Perspectivo, 1995.

MUCHIELLI, Alex L'Identite. Poris: PUF, 1986.

PAGEaUX, Henri-Doniel. De l'imogerie culturelle à l'imoginoire, In: Pierre Brunel e Yvres Chevrel (direction). Précis de Littéroture Comporée. Poris: PUF, 1989

PATLAGEAN, Eveline. A histório do Imaginório, In: LE GOFF, Jocques. A Historio Nova. Trod. Eduordo Brondōo. Sõo Poulo: Mortins Fontes, 1990.

PAZ, Octovio. Signos em rotoşdo. Sōo Poulo: Perspectiva, 1976.

PONTE, Ceccilio. Au correfour du réalisme menveilleux In: Colloque Tenu ò l'Université Lovol, 1988, Québec. Trodition et modemité

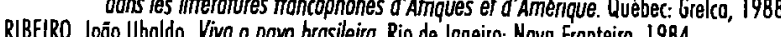

\section{RESUMO: \\ A produção poética e ficcional de escritoras negras brasileiras é o objeto de perquirição deste texto, no qual são sublinhados elementos que, na construção discursiva, produzem novas e engenhosas possibilidades de referências figurativas e temáticas do feminino corpo da negrura no cenário atual da Literatura Brasileira. PALAVRAS-CHAVE:}

Literatura Negra, Literatura Brasileira, Escritoras Negras.

Das cartografias literárias, rostos de personagens femininas pousam o olhar em nós, seus leitores, caligrafados por significantes textuais que parecem solicitar nosso encanto e nossa perda. No entanto, muitos desses perfis, por mais encantatórios que pareçam ser, traduzem miragens do feminino, escritas em um registro alheio e alienante:

A personagem feminina, construída e produzida no registro do masculino, não coincide com a mulher. Não é sua réplica fiel, como muitas vezes crê o leitor ingênuo. É, antes, produto de um sonho alheio e aí ela circula, neste espaço privilegiado que a ficção torna possível.' 
Em sua dupla condição de mulher e negra, a personagem negra feminina tem sido objeto de vícios de representações que espelham não apenas o registro do olhar masculino, mas também convenções e figurações inseminadas pelo registro do racismo. Nas cenas literárias, no Brasil, predominam, com raras exceções, três modelos de ficcionalização do corpo feminino da negrura, inscritos em versos e prosa: a mãe preta, perfil da generosa mãe-de-leite, sempre sorridente e amável, sempre alimentando e ninando a criança branca; a empregada doméstica, uma espécie de força bruta assexuada, de rosto indiferenciado, na função reificada de objeto do lar; e a insinuante mulata, corpo erotizado em excesso, objeto dos desejos "ocultos" do homem branco. Dos poemas de Gregório de Matos às representações narradas pelo romance, televisão e cinema, a figura da mulata percorre uma travessia linear, escrita como signo indicial que, inexoravelmente, aponta para sensualidade, lascívia, malícia, imoralidade, permissividade, vício, egoísmo, cumplicidade e prazer, "qualidades" epitomizadas na luxuriante e sinestésica Gabriela, de Jorge Amado. ${ }^{2}$

Capturado nessas miragens produzidas na e pela linguagem literária, esculpido como letra e forma na materialidade dos significantes textuais, o corpo da mulher negra, literariamente narrado, torna-se uma concha de onde ecoam as vozes narrativas que tecem a personagem feminina à revelia de seu próprio desejo. Esses perfis de mulheres, alheios e alienantes, nunca são auto-definíveis, mas posam nas cartografias do texto como se se quisessem eternamente mirados e perenamente desejáveis. Encobertas por esse véu simultaneamente narcísico e racialista, essas figurações habitam o que Josefina Ludner nomeia "fiç̧ões de exclusão"3 , ficções que tendern a apagar a diferença, e vibram na nossa escrita como "passageiras da voz alheia" ", conforme Brandão.

E é do locus da ficção e da poesia que a escritora negra, em particular, busca rasurar esses vícios de figuração, vestindo a personagem negra feminina com novos significantes que indiciam outras possibilidades de significância e de interferência nos processos de alçamento do corpo feminino como corpo de linguagem. Traduzindo sua condição binária de mulher e negra, as escritoras afro-brasileiras, em muitas de suas produções, elegem o corpo feminino como tema, do qual derivam a artesania da escrita.

2. CF. QUEIROZ, 1975.

3. LUDNER, 1992. p.25.

4. BRANDĀO, 1989, p.19.
Nessas realizações poéticas, alguns significantes, a voz, o corpo, os desejos, são recorrentes, como anéis entrelaçados. Da alquimia do verso emergem novas modulações tímbricas e figurativas que, pelas vias da reversibilidade, disrupção, confrontação e auto-celebração, esculpem, como contraponto às representações tradicionais, engenhosas construções poéticas que ressemantizam a personagem negra na linguagem poética e o próprio corpus literário nacional. Como um lugar privilegiado de ressonâncias e dissonâncias, o corpo metafórico do texto, em muitos poemas, torna-se signo do próprio corpo da mulher, ali inscrito em tons e maquiagens, caligrafados na mordida dura ou leve da palavra:

\author{
Uma gota de leite \\ me escorre entre os seios. \\ Uma mancha de sangue \\ me enfeita entre as pernas. \\ Meia palavra mordida \\ me foge da boca. \\ Vagos desejos insinuam esperanças. ${ }^{5}$
}

Nesse poema de Conceição Evaristo, a metáfora dos "rios vermelhos" recobre o sujeito/mulher (fêmea matriz/força motriz) que, ao se apropriar da palavra, devolvendo-a em estado de semente, provoca a disritmia violentadora dos "tímpanos do mundo" (p.70). Num texto de 21 versos, o pronome Eu repetese por oito vezes em sua forma pessoal, ecoando ainda por mais três nas suas formas oblíquas. O movimento desse Eu, sujeito da enunciação, engravida o texto de referências deslocadas, citando o corpo da mulher como uma paisagem reinaugurada pela auto-nomeação:

Eu-mulher

abrigo da semente

moto contínuo

do mundo. (p.70)

5. EVARISTO, 1995. p.70. 
A metáfora dessa viagem itinerante transita em outros poemas, em imagens espaciais que traduzem os múltiplos continentes da palavra e territórios de linguagens já ocupados pelos idiomas do feminino. Assim,

\section{Na curva do rio trilha}

a

$$
\text { imagem }
$$

poesia sem margem

\section{No leito \\ o corpo se \\ unta de}

verso e prosa.

Reencenado em vários lugares e tempos descontínuos, esse corpo em movimento toma posse da palavra poética e, pelo processo de deslocamento metonímico, produz-se como signo de auto-reconhecimento e júbilo. Vicariamente, esse eu/shifter condensa o sujeito migratório que provoca curvaturas nos rituais de enunciação da dicção feminina. A viagem é, assim, sempre inaugural, pois é na errância da palavra que se produzem a alquimia da voz e os falares feiticeiros, tecendo o sujeito feminino como gesto poético:

Tem uma estrada

deslizando morro acima

escondida

onde uma curva faz serão.

\section{enterrei nela o Vudu das incertezas}

cravado em alfinetes

de mágoas

para liberar o ventre.
Liberar o ventre dos desejos alheios é esvaziá-lo dos sentidos velhos para, então, embebê-lo dos próprios desejos e de palavras sãs. Tórnada instrumento de corte, estilete, a palavra restitui a libido feminina como signo de alegria e prazer. $\mathrm{O}$ eu, assim liberto da voz passiva, rejubila-se, desejante:

\section{Sou eu}

que no leito abraço

mordisco seu corpo

com lascivo ardor

Eu mulher
arranco a viseira da dor
enganosa. ${ }^{8}$

enganosa. ${ }^{8}$

Restituído em seus predicados, esse eu pode agora oferecer-se ao outro, como lugar de conhecimento e expressão, corpo de enunciação:
Gosto sim,
desta história feita,
na folha do papel
absorvendo tintas.
Gosto e quero
o sutil da batalha
entrincheirada e viva
no corpo do poema necessário.

Mas,

mais gosto

do sigiloso verso

emboçado em nossos corpos

no imutável verbo dos sentidos.' 
A mulher negra rememora. Nos burburinhos da memória, sua mais íntima residência, resguarda a tapeçaria de vozes e de olhares, familiares e estrangeiros, que a constituem. Dali germinam seus muitos atos de silêncio e seus indiretos atos de fala

No conto "Maria", de Conceição Evaristo, uma empregada doméstica retorna ao lar, após uma exaustiva jornada de trabalho. Na favela, esperam-na os filhos pequenos, famintos e doentes. Sentada no ônibus, Maria entrega-se às lembranças do dia, dos filhos e às suas dobraduras interiores. Maria pensa, deseja, devaneia. Um homem, seu ex-marido, entra no ônibus, senta-se ao seu lado e passa a sussurrar-lhe palavras mal ouvidas. Presa entre os tempos da memória e os murmúrios do amado, Maria recolhe fragmentos de frases, de momentos mais longínquos e do presente, agrupando-os na sintaxe vertiginosa que a invade:

Ela reconheceu o homem. Quanto tempo, que saudades! Como era difícil continuar a vida sem ele. (...) Ela se lembrou do passado. Do homem deitado com ela. Da vida dos dois no barraco. Dos primeiros enjôos. Da barriga enorme que todos diziam gêmeos, e da alegria dele. Que bom! Nasceu! (...) E o menino, Maria? Como vai o menino? cochichou o homem..$^{10}$

Durante toda a narrativa, a protagonista não emite nenhum som. Ela simplesmente escuta a voz do amado e as suas próprias falas interiores, suas carências mais íntimas, preocupações, estórias de amor e abandono, seus recessos e temores. Sua ação reduz-se a esse ato de reminiscência que a abisma. Das dobras entre o espaço público e o cenário privativo da memória, Maria rumina:

Ela sabia o que o homem dizia. Ele estava dizendo de dor, de prazer, de despedida. Do buraco-saudade no peito dele... Desta vez ele cochichou um pouquinho mais alto. Ela, ainda sem ouvir direito, adivinhou a fala dele: um abraço, um beijo, um carinho no filho. (p.943)

Abruptamente, o homem levanta-se e, com a ajuda de um comparsa,

10. EVARISTO, Callaloo, 1995. p.942. rende, rouba os passageiros e foge. Só então Maria é capturada pelo som ambiente e pelos gritos dos que a acusam de cumplicidade no assalto: "Negra safada, vai ver que estava de coleio com os dois". (...) "Aquela puta, aquela negra safada estava com os ladrões". (...) "Lincha! Lincha! Lincha!" (p.943). Numa narração vertiginosa que mistura as vozes narrativas, engolfando o leitor, já sem saída do texto, como Maria do ônibus, a história encontra seu fim abrupto. Massacrada pelos passageiros, "Maria punha sangue pela boca, pelo nariz e pelos ouvidos"(p.943). S6́ então ouvimos num último extertor (do narrador ou da protagonista?) que "Maria queria muito contar a seu filho que o pai lhe mandava um abraço, um beijo, um carinho"(p.944).

Como nós, leitores, ouvimos a voz de Maria nessa narrativa? Apenas pelos seus atos de reminiscência, dramatizados pela narração como atos de silêncio, plenos de palavras guardadas. Nós a vemos e ouvimos nas bordas da linguagem, nas entrelinhas dos discursos que a coabitam. Seus atos de memória, erigidos entre o som e o silêncio, a locução e a afasia, o velado e o desnudo, o passado e o presente, articulam-se por uma retórica concisa e assindética, alinhavada pelo discurso indireto livre. Desses limites tensionados, sua fala projeta-se pelo texto, em gestos de disseminação e recolha, como um discurso silencioso, já em processo de tornar-se elocução e grito. Nesse conto, o emissor da fala confunde-se com o sujeito da escuta, no burburinho de vozes exteriores e interiores que o constituem como efeito retórico do próprio ato de narrar.

Em "Guarde Segredo", de Esmeralda Ribeiro, narrar é signo de repossessão do próprio sujeito narrado que é, simultaneamente, narrador/ protagonista do enredo ficcional e personagem exemplar da reescrita da memória literária nacional. Nesse conto, Clara, uma jovem mulata, narra, em carta a uma amiga, as razões do seu desaparecimento, após matar Cassi Jones, seu amante. Curiosamente, na história literária brasileira, Cassi Jones e Clara são os protagonistas da novela Clara dos Anjos, de Lima Barreto, narrativa com a qual o conto de Esmeralda Ribeiro dialoga.

Em Barreto, a ingênua e meiga mulata Clara é engravidada e abandonada por Cassi Jones, pequeno-burguês branco dos subúrbios cariocas. A novela de Lima Barreto fecha-se com as desventuras de Clara, num coro de lamentações e recriminações do narrador que critica a educação familiar das jovens negras, vítimas fáceis do fetiche dos namorados brancos e do desejo da brancura. No texto de Esmeralda Ribeiro, Clara não veste o perfil de vítima sacrificial e ocupa o lugar de uma instância transformadora, fazendo-se agente de seu próprio destino. Ao dramatizar o enredo amoroso entre o branco e a 
mulata, a escritora aborda o texto de Barreto pela analogia temática (o romance inter-racial), mas dele também se distancia pela arquitetura da trama e pela diferença na figuração da personagem feminina: a Clara de "Guarde Segredo" é o inverso da protagonista de Clara dos Anjos. Ela mata o amante e, sem sentimentos de culpa ou recriminações, inverte o desfecho do enredo, tornando a figura do namorado objeto de reflexões na carta/conto que envia ao leitor/ narratário:

Quando voltava para casa de vovó, fui interpelada por uma senhora gorda. Parecia muito com Cassi Jones. Ela cruzou o meu caminho e ficou parada na minha frete. Insultou-me tanto!... Disse coisas horríveis do tipo: "Você é a quinta negra que meu filho deflorou e também não vai ficar com ele. Nesse exato momento está com outra garota". (...) Encontrei-os na saleta de um hotelzinho. Ela fugiu, mas ele não teve tempo de reagir. Foram tantas facadas!... (...) Demorei menos de uma hora para chegar à casa de vovó. (...) Fui entrando, entrando e ouvi o Lima Barreto escrevendo à máquina. Conversavam e riam muito. Por um momento, juro tê-lo ouvido dizer: "Esperávamos por você. Entre". Eu pensava: "Tudo está acontecendo ao mesmo tempo"."

No jogo intertextual e na friç̧ão entre o texto exemplar da tradição e a sua rasura, a narrativa de Esmeralda Ribeiro engendra outras vias de ficcionalização da mulher negra no contexto contemporâneo. Assim, o texto de Lima Barreto é contemplado não por uma filiação especular, mas por uma relação descontínua que fissura e suplementa a narrativa de origem. Ao acessar o suplemento da diferença, a metaficcionalidade textual passa a ser gerenciada não mais pela familiaridade abismática e especular da analogia, mas sim pela via da contigüidade que produz o texto novo como moto-descontínuo, índice de deslocamento. O destinatário da carta/conto faz-se, pois, plural. É tanto a amiga, narratário ausente que recebe a missiva, quanto nós, seus leitores e intérpretes da história literária que a narrativa subverte. Tornado personagem, Lima Barreto erra pelo conto de Esmeralda Ribeiro, evocado como fotografia e fantasma que, oscilando pelos planos da presença e da ausência, do visível e do invisível, assombra o texto/casa de Clara. Ambiguamente celebrado e barrado, esse personagem é exorcizado pela diç̧ão jubilatória que a narrativa lhe empresta, fazendo coincidir a voz fantasmática do personagem/escritor Lima Barreto de
"Guarde Segredo" com o desejo implícito do narrador de Clara dos Anjos:

- Você matou Cassi Jones? - ele interrompeu o meu devaneio.

- Matei - respondi. "Como soube disso?", interroguei-me.

- Bravo! Esse era o outro final que queria para o cafajeste do Cassi Jones. (p.29)

Sobre o cadáver de Cassi Jones, metonímia do destino lacrimoso e indesejável da Clara barretiana, a narrativa contemporânea escreve a sua diferenciadora alteração, como texto suplementar que evoca a tradição, citandoa, mas que também a rasura, plissando-a. As referências tradicionais, recitadas em estado de diferença, criam, assim, engenhosas possibilidades de desdobramentos. Esse movimento de alternância, de filiação e distanciamento, de analogia e ruptura, é saborosamente traduzido pela avó da pós-moderna Clara:

"Tinha que ser assim, minha neta", e continuou: "Nós não devemos aceitar o destino com resignação". (p.29)

Ao final de sua narração, Clara confessa-se aliviada por ter revelado sua estória, mas, consciente de que "ainda existe o balanço e a gangorra, apesar do mato ter tomado conta de tudo", pede à amiga que "guarde eternamente este segredo" (p.29). Guardar segredo é, aqui, um ato de recesso voluntário e estratégico. Resguardando na esfera do privado a cena de ruptura, tornada entretanto pública pela inconfidência da escritura, o gesto da narradora/escritora simula, com eficácia, a diç̧ão da mulher negra personagem e escritora, uma voz tensionada entre a necessidade do silêncio e o impulso da locução, como bem observa Carole Boyle Davies:

E é esta tensão entre articulação e afasia, entre as limitações da língua falada e as possibilidades de expressão, entre o espaço para certas formas de discurso e a falta de espaço para o discurso da mulher negra, a sua postulação entre o público e o privado, que essas escritoras abordam. ${ }^{12}$

Quebrar os ritos de ficcionalização da mulher negra, tecer outras dobras, desdobrar seus contornos e alinhavos, ferir as imagens viciadas são atos 
performados por esses textos, que desvelam, na rasura dos véus da tradição poética e ficcional, outras possíveis silhuetas do feminino corpo da negrura. Assim, podemos afirmar com Barthes:

"Desvelar" não é tanto retirar o véu como despedaçá-lo: no véu, só se comenta, geralmente, a imagem daquilo que se esconde ou subtrai. Mas o outro sentido da imagem é igualmente importante - o forrado, o tênue, o seguido; atacar o escrito mentiroso é separar o sentido, reduzir o véu a dobras quebradiças. ${ }^{13}$

Esses textos, aqui brevemente abordados, constituem parte da produção literária afro-brasileira, reeditada e traduzida em vários outros países, apesar das dificuldades de edição, divulgação e do pouco interesse crítico que encontram no cenário nacional. Mesmo sem privilegiar categorias de "gênero", "raça" e "etnias" como referenciais que, por si sós, informam as qualidades de um texto, nós, comentadores literários, não podemos olvidar os papéis que essas mesmas categorias têm desempenhado na constituição dos cânones, nas escolhas e exclusões dos escritos que são eleitos ou não para serem lidos e celebrados por nós. Esses textos poéticos e ficcionais, na hilética composição dos seus significantes e na artesania da sua linguagem, pincelam o feminino corpo da negrura em instigantes e novas visagens que se posam para nossos olhares. Como não mirá-los? Por que ignorá-los? Afinal, como afirma Toni Morrison, "all of us, readers and writers, are bereft when criticism remains too polite or too fearful to notice a disrupting darkness before its eyes"14.

13. BARTHES, 1993. p.230.

14. MORRISON, 1992. p.91.

\section{ABSTRACT:}

The literary production of Black women writers is the main theme of this paper, in which I adress some disrupting discoursive constructions that create new references for the fabulation of the feminine figures in the context of KEW-WORDS: contemporary Brazilian Literature.

African-Brazilian Literature, Brazilian Literature, Black Women Writers.
REFERENACAS BIBLOGRÁFICAS

ALVES, Miriom. Vudu. In: ALVES, M.A., DURHAM, C.R. (eds.) Finally us. contemporary Block brosilions women witers. Ist edition of bilinguol text. USA: Three Continents Press, 1995

. Pedosos de Muther. In: MARTINS, L.M., PERES P. DUPHAM CR. ROWELL, C. (eds)... Collaloo, Afficon Brozilion Literonse, o Speciol issue, v. 18, n.4. Lowisiona/USA: The Johns Hopkins University Press, 1995.

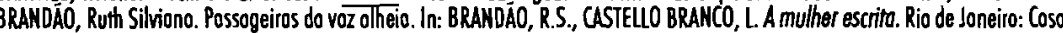
Morio Editoro, 1989.

DAVIES, C. B. Black women writing ond identily: mingrotions of the subject. London ond New York: Routledge, 1994. EVARISTO, Conceisgóo. Eu-Mulher. In: ALVES, M.A., DURHAM, C.R. (eds.) Finally us, op.cit.

Morio. In: Colloboo, op.cit.

GUIMTARÄES, Geni. Verso nu. In: Finally us, op.cit.

LUDNER, I. "Ficciones de exclusión". In: HOLLANDA, H. B. de (org.) ¿ Y Y nosotitas latinoomericanos?, estudos sobre gênero e rosco Sóo Poulo: Fundocĩo Memariol do Américo Lotina, 1992.

MORRISON, Toni. Plaving in the dark, whiteness ond the literory imoginotion. Combridge ond London: Horvord Universiny Press,

QUEIROZ, I. de, J. Preconceito de cor e a mulato no literatura brosileiro. Sõo Paulo: Afico, 1975.

RIBEIRO, Esmerolddo. Continente sem fim. In: Finally us, op.cit.

Guorde Segredo. Cadernos Negros 14, contos. Sö́o Poulo: Quilombhoie, 1991. 